\title{
Exploring the use of flexibility indices in low carbon power systems
}

DOI:

10.1109/ISGTEurope.2012.6465757

Link to publication record in Manchester Research Explorer

\section{Citation for published version (APA):}

Ma, J., Silva, V., Belhomme, R., Kirschen, D. S., \& Ochoa, L. F. (2012). Exploring the use of flexibility indices in low carbon power systems. In IEEE PES Innovative Smart Grid Technologies Conference Europe/IEEE PES Innovative. Smart Grid Technol. Conf. Europe https://doi.org/10.1109/ISGTEurope.2012.6465757

\section{Published in:}

IEEE PES Innovative Smart Grid Technologies Conference Europe|IEEE PES Innovative. Smart Grid Technol. Conf. Europe

\section{Citing this paper}

Please note that where the full-text provided on Manchester Research Explorer is the Author Accepted Manuscript or Proof version this may differ from the final Published version. If citing, it is advised that you check and use the publisher's definitive version.

\section{General rights}

Copyright and moral rights for the publications made accessible in the Research Explorer are retained by the authors and/or other copyright owners and it is a condition of accessing publications that users recognise and abide by the legal requirements associated with these rights.

\section{Takedown policy}

If you believe that this document breaches copyright please refer to the University of Manchester's Takedown Procedures [http://man.ac.uk/04Y6Bo] or contact uml.scholarlycommunications@manchester.ac.uk providing relevant details, so we can investigate your claim.

\section{OPEN ACCESS}




\title{
Exploring the Use of Flexibility Indices in Low Carbon Power Systems
}

\author{
Juan Ma, Student Member, IEEE, Vera Silva, Member, IEEE, Régine Belhomme, Member, IEEE, \\ Daniel S. Kirschen, Fellow, IEEE, and Luis F. Ochoa, Senior Member, IEEE
}

\begin{abstract}
The term 'flexibility' describes the system's ability to cope with variations and uncertainties in both generation and demand side and maintain the system reliability with minimum cost. This work presents two different ways of establishing flexibility metrics so that the flexibility of individual units as well as the whole system can be quantified offline without using complex multi-temporal simulations. The first metric is named Normalized Flexibility Index' (NFI). It is obtained by analyzing the adjustable space of generators and the flexibility level is expressed as a normalized positive number less than unity. The second index, named Loss of Wind Estimation (LOWE), assesses the flexibility level of a system by its capability for accommodating wind. It measures the probability that wind curtailment occurs during a year. The performance and potential applications of the two indices are discussed in the paper. The results indicate these indices provide a convenient way to get a quick, consistent overview of how flexibility different systems are.
\end{abstract}

Index Terms-- Flexibility, wind integration, normalized flexibility index, Loss of Wind Estimation

\section{INTRODUCTION}

$\mathrm{T}^{\mathrm{H}}$ HE term flexibility describes the system's ability to cope with variations and uncertainties and maintain the system reliability with minimum cost. In the literature, the concept of flexibility lacks quantitative metrics that could be used for planning or other purposes $[1,2]$. Most studies about flexibility rely on multi-temporal simulation of power system operation $[3,4]$. This paper presents two different ways of establishing flexibility metrics so that the flexibility of individual units as well as the whole system can be quantified.

The first metric is named Normalized Flexibility Index (NFI). It is used to identify the flexibility level of single generator units and indicate their contributions to the whole system's flexibility.

The second metric is called Loss of Wind Estimation (LOWE). It indirectly illustrates the flexibility level of a system through its ability to accommodate wind. It measures the probability that wind curtailment occurs in a system during a year.

This paper is organized as follows: Section II introduces the normalized flexibility index and its validation is conducted

J Ma and L F Ochoa are with the School of Electrical and Electronic Engineering at The University of Manchester, Manchester, UK. (e-mail: juan.ma@postgrad.manchester.ac.uk, luis_ochoa@ieee.org)

D S Kirschen is with the University of Washington, Seattle, USA. (e-mail: kirschen@washington.edu)

V Silva and Regine Belhomme are with EDF R\&D, Clamart, France. (email: vera.silva@edf.fr, regine.belhomme@edf.fr) in Section III. Section IV presents the LOWE index and it is verified in Section V.

\section{NORMALIZED FLEXIBILITY INDEX (NFI)}

A flexible power system should have sufficient ramping capability and enough operating reserve to cope with the forecasted and un-forecasted variations in the net demand. The requirements are usually fulfilled by flexible generation, conventional storage (e.g., hydro pumped storage), and flexible demand (when available). In this work, we take flexible thermal generators as an example to develop the flexibility indices.

All generation units may contribute to up/downward reserve. However, their contribution to upward reserve is limited by their ramp-up rate and spare upward capacity, i.e., the difference between their scheduled output and the maximum capacity. In a similar way, their ramp-down rate and spare downward capacity, i.e., the difference between the scheduled output and the minimum stable generation, help to build the downward reserve. Mathematically, this can be summarized as:

$$
\begin{array}{r}
r_{\text {up }}(i, t) \leq u(i, t) \min \left\{\mathrm{P}_{\max }(i)-p(i, t), \tau \operatorname{Ramp}_{\text {up }}(i)\right\} \\
r_{\mathrm{dn}}(i, t) \leq u(i, t) \min \left\{p(i, t)-\mathrm{P}_{\text {min }}(i), \tau \operatorname{Ramp}_{\mathrm{dn}}(i)\right\} \\
\forall i \in A, \forall t \in T
\end{array}
$$

Here, $r_{\mathrm{up}}(i, t)$ and $r_{\mathrm{dn}}(i, t)$ are the up and down reserve that can be provided by thermal generator $i$ (part of system A) at hour $t . \mathrm{P}_{\max }(i)$ and $\mathrm{P}_{\min }(i)$ are the maximum capacity and the minimum stable generation of generator $i$. Ramp up $(i)$ and $\operatorname{Ramp}_{\mathrm{dn}}(i)$ indicates the ramping up and down rate of generator $i$, and $\tau$ is the time available for generators to ramp up/down their output. To cope with the hourly variations in net demand, here $\tau$ is assumed to be 1 hour. $p(i, t)$ describes the scheduled output of generator $i$ at hour $t$.

The flexibility index flex is designed here to represent the adjustable range for each generating unit. Due to the variable size of units, the index must be normalized for comparison purposes:

$$
f l e x(i)=\frac{\frac{1}{2}\left[\mathrm{P}_{\text {max }}(i)-\mathrm{P}_{\text {min }}(i)\right]+\frac{1}{2}[\operatorname{Ramp}(i)]}{\mathrm{P}_{\text {max }}(i)} \quad \forall i \in A
$$

Here $\operatorname{Ramp}(i)$ is the average value of $\operatorname{Ramp}_{\text {up }}(i)$ and $\operatorname{Ramp}_{\mathrm{dn}}(i)$, which indicates the speed of a unit to change its 
TABLE I

FLEXIBILITY INDEX FOR IEEE RTS 26-UNIT SYSTEM

\begin{tabular}{c|c}
\hline Name & NFI \\
\hline 26-unit system & 0.5352 \\
\hline U12_Oil/Steam & 0.8000 \\
\hline U20_Oil/CT & 0.2100 \\
\hline U76_Coal/Steam & 0.7266 \\
\hline U100_Oil/Steam & 0.6875 \\
\hline U155_Coal/Steam & 0.5395 \\
\hline U197_Oil/Steam & 0.5204 \\
\hline U350_Coal/Steam & 0.4357 \\
\hline U400_Nuclear & 0.4691
\end{tabular}

position within $\mathrm{P}_{\text {max }}(i)-\mathrm{P}_{\text {min }}(i) . f l e x(i)$ is the flexibility index of thermal generator $i$.

Because the flexibility contribution of each single generator is proportional to its capacity in the whole system, the flexibility index for the whole system, FLEX, can be calculated by the weighted average of flex $(i)$ of individual generators. The weight for each generator equals to its capacity in proportion to the whole system. Finally, FLEX $_{A}$ is expressed as:

$$
\operatorname{FLEX}_{A}=\sum_{i \in A}\left[\frac{\mathrm{P}_{\text {max }}(i)}{\sum_{i \in A} \mathrm{P}_{\max }(i)} \times \operatorname{flex}(i)\right] \quad \forall i \in A
$$

\section{VALIDATION OF THE NFI}

In this section the normalized flexibility index (NFI) is tested on IEEE RTS 26-unit system [5]. This system is chosen because of their diversity in unit types and available technical parameters. Using the method proposed in the previous section, the NFI is calculated accordingly. The results are listed in Table I.

According to the indices, the generation units in the power system can be categorized into two groups: flexible and nonflexible units. Whether a single generator is flexible or not is defined by comparing its individual flexibility index with the whole system's flexibility level. If the index of one specific unit is higher than the system's level, this unit is regarded as flexible in this system. Likewise, non-flexible units are those with a flexible index lower than the system level. In this case, the 26-unit system has an index level of 0.5352 . Thus, for this system, units U12, U76, U100, and U155 are the flexible units, whereas U20, U197, U350 and U400 are non-flexible units. It is important to define the flexible and non-flexible units on a system-based criterion, because a flexible unit in one system may not be so flexible in another system.

Based on their flexibility index levels, these units are reorganized to form three new test systems. Generation Mix 1 consists of the most flexible types U12, U76, U100, and U155 with 9 units of each type. Generation Mix 2 is made of mixed flexible types U12, U76, U350, and U20 with 7 units of each type. Generation Mix 3 contains the least flexible types U197, U400, U350 and U20 with 5 units of each type. The numbers of units in each group are chosen to make these systems have comparable levels of installed generation capacity.

The three generator groups are tested in the same scenario:
TABLE II

WIND UTILIZATION RESULTS WITH DIFFERENT FLEXIBILITY INDICES

\begin{tabular}{c|c|c|c}
\hline $\begin{array}{c}\text { Generation Mix } \\
\text { APL=2200MW } \\
\text { Wind Capacity=880MW }\end{array}$ & $\begin{array}{c}\text { Total } \\
\text { capacity } \\
\text { (MW) }\end{array}$ & NFI & $\begin{array}{c}\text { Wind } \\
\text { Curtailment }\end{array}$ \\
\hline HFM 9*(U12+U76+U100+U155) & 3087 & 0.6333 & $19.41 \%$ \\
\hline MFM 7*(U12+U76+U350+U20) & 3206 & 0.4836 & $58.01 \%$ \\
\hline LFM 5*(U197+U400+U350+U20) & 3868 & 0.4621 & $89.33 \%$ \\
\hline $\begin{array}{c}\text { 26units system } \\
\text { (Mix of all type of units) }\end{array}$ & 3105 & 0.5352 & $51.52 \%$ \\
\hline
\end{tabular}

serving the same load with annual peak load of 2200MW and accommodating $880 \mathrm{MW}$ of wind capacity. The normalized annual load profile and wind profile are obtained from the 2005 UK system to represent the realistic variations [6]. The demand and wind data will be used in a unit commitment model [7], which is able to dispatch the thermal generation and wind generation. To validate the proposed flexibility index, realistic wind curtailment is used for comparison. This is calculated by performing the unit commitment over the time horizon of 24 hours during 365 days. The test results are shown in Table II.

As expected, the high flexible group with the highest index 0.6333 is able to utilize $80.6 \%$ of total potential wind generation (only $19.4 \%$ of wind is curtailed). The medium flexible group, with an index of 0.4836 , is capable of absorbing $42 \%$ of total wind generation $(58 \%$ of wind is curtailed). The low flexible system, with the lowest index, is only able to handle $10.7 \%$ of wind generation which means almost $90 \%$ of the wind generation has to be curtailed.

From Table II it can also be seen that the index is consistent when evaluating the flexibility level of the 26-unit system. The system has an index of 0.5352 which is between the highest and medium flexible mixes. This also is true for the corresponding wind curtailment.

However, it can be seen that there is no linear relation between the NFI index and the realistic wind curtailment. This is mainly because the wind curtailment is not the linear result of the unit commitment, and the calculation of the NFI is not linearized. Therefore, NFI is only able to describe the flexibility level but cannot be used to accurately measure the wind curtailment.

Apart from the capability of indicating the flexibility levels of different systems, the normalized flexibility index can also be used to estimate the effects of new investment on the flexibility of original system. This is important because a new generator with an index higher than the original system flexible index will enhance the system flexibility, whereas a generator with a lower index may deteriorate the overall system flexibility. With this offline calculation of flexibility index, it is very convenient to evaluate the contribution of new invested generators to flexibility without conducting complex time-consuming simulations on realistic systems.

\section{LOSS OF WIND ESTIMATION (LOWE)}

From a demand-generation balancing perspective, wind curtailment occurs whenever the system does not have sufficient flexibility to cope with the variations in wind 


\section{Accepted Paper}

generation and therefore it appears more often in a nonflexible system than a flexible one. This provides another way of assessing the system flexibility, namely by the probability that wind curtailment occurs.

The second flexibility index in this work is created based on the this concept and is named as Loss of Wind Estimation (LOWE). The LOWE index represents the estimated probability that wind curtailment occurs in a system during a year.

Wind curtailment occurs most likely in three situations:

1) Net demand is lower than the Minimum Load Level (MLL) of system;

2) Net demand drops sharply but committed generators do not have sufficient ramp-down rate or cannot be shut down immediately; and,

3) Net demand increases sharply but committed generators do not have sufficient ramp-up rate or offline generators cannot be start up immediately.

Here, it is assumed that the three events are independent. The probability of the occurrence of each event is represented by $\mathrm{P}\left(\mathrm{V} \_\mathrm{MLL}\right), \mathrm{P}\left(\mathrm{V} \_\right.$Ramp-up) and $\mathrm{P}\left(\mathrm{V} \_\right.$Ramp-dn $)$, where the character ' $\mathrm{V}$ ' means the corresponding constraint is violated. Thus, the probability for each event not to occur is equal to 1-P(V_MLL) , 1-P(V_Ramp-up) , 1-P(V_Ramp-dn), respectively. The probability of system without any wind curtailment is the joint probability of the three, given none of the three events happens, as shown below:

$\mathrm{P}($ NoWC $)=$

$$
\left(1-\mathrm{P}\left(\mathrm{V} \_ \text {MLL }\right)\right) \times\left(1-\mathrm{P}\left(\mathrm{V}_{-} \text {Ramp-up }\right)\right) \times\left(1-\mathrm{P}\left(\mathrm{V}_{-} \text {Ramp-dn }\right)\right)
$$

where $\mathrm{P}(\mathrm{NoWC})$ is the probability that wind curtailment does not occur in the system.

Accordingly, the Loss of Wind Estimation (LOWE) is calculated by:

$$
\begin{aligned}
& \text { LOWE }=1-\mathrm{P}(\mathrm{NoWC})= \\
& 1-\left(1-\mathrm{P}\left(\mathrm{V}_{-} \mathrm{MLL}\right)\right) \times\left(1-\mathrm{P}\left(\mathrm{V}_{-} \text {Ramp-up }\right)\right) \times\left(1-\mathrm{P}\left(\mathrm{V}_{-} \text {Ramp-dn }\right)\right)
\end{aligned}
$$

\section{A. Calculation of $\mathrm{P}\left(\mathrm{V} \_\mathrm{MLL}\right), \mathrm{P}\left(\mathrm{V} \_\right.$Ramp-up $)$and}

\section{$\mathrm{P}(\mathrm{V}$ Ramp-dn)}

$\mathrm{P}(\mathrm{V}$ _MLL) represents the probability of net demand drops below minimum load level (MLL) of the system and it is expressed by:

$$
\mathrm{P}\left(\mathrm{V} \_\mathrm{MLL}\right)=\mathrm{P}(\text { Netdemand } \leq \mathrm{MLL})
$$

The net demand varies with hours during a year and it is regarded as a random variable in this problem. In statistical analysis, probability of a random variable less than or equal to a fixed number $\mathrm{A}$ forms the cumulative distribution function (CDF) of this random variable. For every real number $A$, the $\mathrm{CDF}$ of a real-valued random variable $\mathrm{x}$ is given by:

$$
F_{x}(\mathrm{~A})=P(x \leq \mathrm{A})
$$

In our case, the random variable is the net demand and number A is replaced by minimum load level (MLL). So $\mathrm{P}\left(\mathrm{V} \_\mathrm{MLL}\right)$ is the value of CDF of net demand evaluated at MLL, as shown in (8).

$$
\mathrm{P}\left(\mathrm{V}_{-} \mathrm{MLL}\right)=\mathrm{F}(\mathrm{MLL})
$$

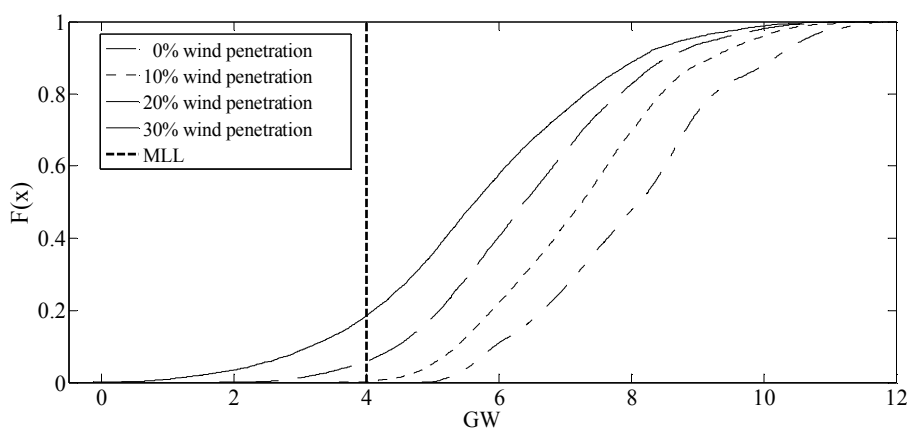

Fig. $1 \mathrm{CDF}$ of net demand with $0,10,20$, and $30 \%$ wind penetration

As an example, the normalized load profiles and wind profiles of UK in 2005 [6] are used here to represent the realistic variations. Load profiles are multiplied by the $12 \mathrm{GW}$ annual peak load, and wind profiles are scaled up by different wind capacities to show the various wind penetrations (as percentage of annual demand). CDFs of net demand under 0 , 10, 20, and 30\% wind energy penetrations are shown in Fig. 1.

It is seen that with more wind penetration, CDF of net demand moves towards the left. This will result in larger possibilities of net demand to cross the vertical line (the minimum load level), and thus larger P(V_MLL) is observed. The minimum load level is system specific and case specific. Here, $4 \mathrm{GW}$ was considered as an example. The statistical performance of $\mathrm{CDF}$ indicates that it is more likely to have wind curtailment in the situations with larger wind capacities.

To get the value of $\mathrm{P}\left(\mathrm{V} \_\right.$Ramp-up) and $\mathrm{P}\left(\mathrm{V} \_\right.$Ramp-dn $)$, similar methods are used.

$$
\begin{gathered}
\mathrm{P}\left(\mathrm{V} \_ \text {Ramp-up }\right)=\mathrm{P}\left(\mathrm{Up} \_ \text {Variation } \geq \sum \text { Ramp-up }\right) \\
=1-\mathrm{P}\left(\mathrm{Up} \_ \text {Variation } \leq \sum \text { Ramp-up }\right)=1-\mathrm{F}\left(\sum \text { Ramp-up }\right) \\
\mathrm{P}\left(\mathrm{V} \_ \text {Ramp-dn }\right)=\mathrm{P}\left(\mathrm{Dn} \_ \text {Variation } \geq \sum \text { Ramp- dn }\right) \\
=1-\mathrm{P}\left(\text { Dn_Variation } \leq \sum \text { Ramp- } \mathrm{dn}\right)=1-\mathrm{F}\left(\sum \text { Ramp- dn }\right)
\end{gathered}
$$

\section{B. Calculation of the LOWE}

By rearranging the equations (5), (8), (9), (10), the LOWE is expresses as:

$$
\text { LOWE }=1-(1-F(M L L)) \times\left(F\left(\sum \text { Ramp-up }\right)\right) \times\left(F\left(\sum \text { Ramp-dn }\right)\right)(11)
$$

Given the same percentage of wind energy penetration, the system with lower LOWE index value is obviously more flexible. The application of this index is not limited to flexibility comparison. For example, it can be used to estimate the maximum allowable wind penetration in an existing system. If a tolerant standard of wind curtailment is given, i.e., $\mathrm{Q} \%$ of time during a year, the LOWE index is then compared with $\mathrm{Q} \%$ to assess the flexibility of system. The index is increased with the percentage of wind penetration, and once it is found to be larger than $\mathrm{Q} \%$, the corresponding wind penetration $\mathrm{W} \%$ is deemed as the maximum allowable wind penetration in this system. Furthermore, the effects of new invested generators on system flexibility can be seen from the LOWE index. Whether this index will be reduced or increased and to what extent the value is changed are both indicating the flexibility of the new system.

Several aspects between the LOWE index and the Loss of Load Probability (LOLP) are compared in Table III. The 


\section{Accepted Paper}

TABLE III

COMPARISONS BETWEEN LOLP AND LOWE

\begin{tabular}{l|l|l}
\hline Concept & \multicolumn{1}{|c}{ LOLP } & \multicolumn{1}{c}{ LOWE } \\
& $\begin{array}{l}\text { For what percentage of } \\
\text { time during a year, the } \\
\text { available generation is } \\
\text { likely to fall short of the } \\
\text { demand during a year }\end{array}$ & $\begin{array}{l}\text { For what percentage of } \\
\text { time during a year, the } \\
\text { potential wind generation } \\
\text { output is likely to be } \\
\text { curtailed }\end{array}$ \\
\hline Function & $\begin{array}{l}\text { Measurement of } \\
\text { generation adequacy }\end{array}$ & $\begin{array}{l}\text { Measurement of system } \\
\text { flexibility }\end{array}$ \\
\hline Criterion & $\begin{array}{l}\text { Whether system has } \\
\text { sufficient capacity and } \\
\text { auxiliary services to }\end{array}$ & $\begin{array}{l}\text { Whether system has } \\
\text { sufficient flexibility to } \\
\text { follow up the variations in } \\
\text { wind generation }\end{array}$ \\
\hline $\begin{array}{l}\text { Consequence of } \\
\text { exceeding the } \\
\text { standard }\end{array}$ & $\begin{array}{l}\text { LOLP larger than } \\
\text { acceptable standard } \\
\text { indicates that the }\end{array}$ & $\begin{array}{l}\text { LOWE larger than } \\
\text { acceptable standard } \\
\text { indicates that wind } \\
\text { penetration is beyond the } \\
\text { inadequacy in generation } \\
\text { inam level that system } \\
\text { flexibility can handle. }\end{array}$ \\
\hline
\end{tabular}

application of the latter in assessing generation adequacy is an internationally accepted practice. The comparison shows that the proposed index, also a statistical index, has similar characteristics with widely used LOLP.

\section{VALIDATION OF THE LOWE INDEX}

To validate the effectiveness of the LOWE index three test systems will be used. The base system, also called Medium Flexible (MF) system, is comprised of three main thermal technologies (in decreasing order of flexibility): combined cycle gas turbine (CCGT), Coal and Nuclear. The technical parameters of each technology are listed in Table IV.

A highly flexible system (HF system) is obtained by replacing all nuclear plants in the MF system with CCGT. A less flexible system (LF system) is obtained by replacing all CCGT plants with nuclear plants. The components of each system are shown in Table V.

The determination of the minimum load level (MLL), $\sum$ Ramp-up and $\sum$ Ramp-dn usually depends on operation experience. To demonstrate the application of the LOWE index, the MLL in each system is assumed to be $50 \%$ of the summation of all units' minimum stable generation (for the particular system). For $\sum$ Ramp-up and $\sum$ Ramp-dn, they are assumed to be the summation of all units' ramping capability. This is to produce a scenario where all the units are participating in ramping. These assumptions are only used to create an equal basis for the comparison. The corresponding parameters for the three test systems are listed in Table VI.

Comparisons between the LOWE index and the simulation results of wind curtailment probability are plotted in Fig. 2. The proposed index shows a very good approximation to the operational process.

The proposed index in this case is calculated based on rough assumptions for the MLL. In practice, the MLL is both system-specific and case-specific. The more accurate information that can be used to determine the MLL, the better estimation can provided by the LOWE index.

\section{CONCLUSIONS}

Two flexibility indices are proposed in this paper to evaluate the flexibility of power systems. The main purpose is
TABLE IV

TECHNICAL PARAMETERS FOR CCGT, COAL AND NUCLEAR PLANTS

\begin{tabular}{l|c|c|c|c|c|c|c|c}
\hline & $\begin{array}{c}\text { Pmin } \\
\text { (MW) }\end{array}$ & $\begin{array}{l}\text { Pmax } \\
(\mathbf{M W} \\
\text { ) }\end{array}$ & $\begin{array}{c}\text { Ramp } \\
\text { up } \\
\text { uW/h) }\end{array}$ & $\begin{array}{c}\text { Ramp } \\
\mathbf{d n} \\
\mathbf{M W} / \mathbf{h})\end{array}$ & $\begin{array}{c}\text { Minup } \\
\text { (h) }\end{array}$ & $\begin{array}{c}\text { Mindn } \\
\text { (h) }\end{array}$ & $\begin{array}{c}\text { Fuel } \\
\text { Cost } \\
(\mathbf{\$} / \mathbf{M W h})\end{array}$ & $\begin{array}{c}\text { STC } \\
\mathbf{( \$ )}\end{array}$ \\
\hline CCGT & 250 & 500 & 400 & 500 & 3 & 3 & 40 & 1200 \\
\hline Coal & 250 & 500 & 200 & 250 & 4 & 4 & 30 & 3000 \\
\hline Nuclear & 450 & 500 & 10 & 25 & 8 & 54 & 20 & 0 \\
\hline
\end{tabular}

TABLE V

COMPONENTS OF THE THREE TEST SYSTEMS

\begin{tabular}{l|c|c|c}
\hline Number of plants & CCGT & Coal & Nuclear \\
\hline HF_system & 17 & 13 & 0 \\
\hline MF_system & 12 & 13 & 5 \\
\hline LF_system & 0 & 13 & 17 \\
\hline
\end{tabular}

TABLE VI

MLL, $\sum$ Ramp-up AND $\sum$ Ramp-dn FOR THE THREE TEST SYSTEMS

\begin{tabular}{l|c|c|c}
\hline & $\begin{array}{r}\text { MLL } \\
\text { (MW) }\end{array}$ & $\begin{array}{r}\sum \text { Ramp-up } \\
\text { (MW/h) }\end{array}$ & $\begin{array}{r}\sum \text { Ramp-dn } \\
\text { (MW/h) }\end{array}$ \\
\hline HF system & 3750 & 9400 & 11750 \\
\hline MF system & 4250 & 7450 & 9375 \\
\hline LF system & 5450 & 2770 & 3675 \\
\hline
\end{tabular}

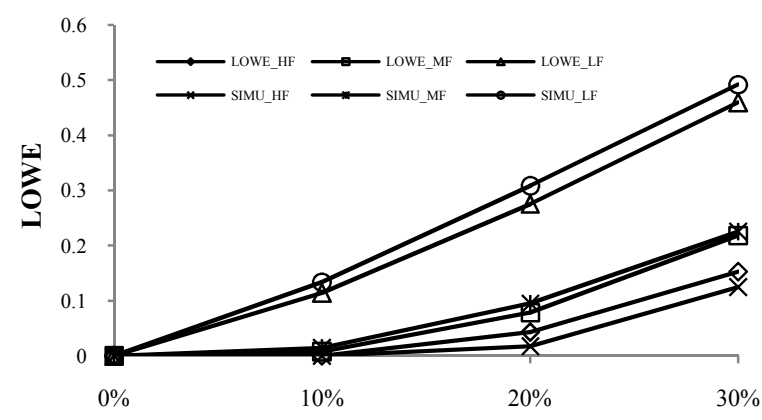

Potential Wind Penetration (\% of annual load)

Fig. 2. Comparisons between the LOWE index and UC-based results

to provide an offline estimation of the flexibility level without implementing complex time-consuming simulations with an operational model (unit commitment). From the case studies, it is seen that the proposed indices have a good consistency with the simulated results. These indices can also be extended to take into account alternative sources of flexibility.

\section{REFERENCES}

[1] B. C. Ummels, "Power System Operation with Larg e-Scale Wind Power in Liberalised Environments," PhD, University Delft, 2009.

[2] "Operating the electricity transmission networks in 2020," National Grid, June 2011.

[3] V. S. V. Silva, "Value of flexibility in systems with large wind penetration," PhD Thesis, Imperial College London, London, 2010.

[4] F. Bouffard and M. Ortega-Vazquez, "The value of operational flexibility in power systems with significant wind power generation," in IEEE Power and Energy Society General Meeting, 2011.

[5] C. Grigg, et al., "The IEEE Reliability Test System-1996. A report prepared by the Reliability Test System Task Force of the Application of Probability Methods Subcommittee," Power Systems, IEEE Transactions on, vol. 14, pp. 1010-1020, 1999.

[6] R. Green and N. Vasilakos, "Market behaviour with large amounts of intermittent generation," Energy Policy, vol. 38, pp. 3211-3220, 2010.

[7] N. P. Padhy, "Unit commitment-a bibliographical survey," Power Systems, IEEE Transactions on, vol. 19, pp. 1196-1205, 2004. 


\section{BIOGRAPHIES}

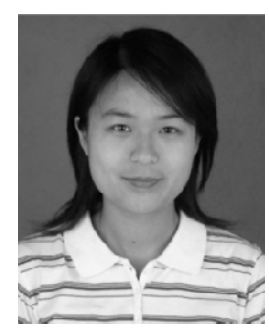

Juan Ma was born in China, 1983. She received her B.Sc. and M.Sc. degree in Electrical Engineering from Tsinghua University, China, in 2006 and 2008. She received the Ph.D. from The University of Manchester, UK, in 2012. Her main research interest is power system operation with wind penetration and electricity market.

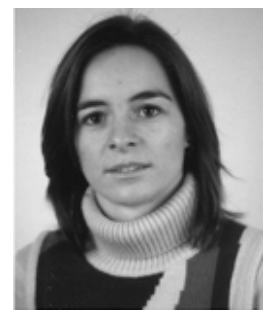

Vera Silva received a B.Sc. and M.Sc. degrees from the University of Porto, Portugal, in 1999 and 2003, respectively, and a Ph.D in Electrical Engineering from the Imperial College London in 2010. She is a Project Manager and Research Engineer at the Department of Economic and Technical Analysis of Energy Systems in the R\&D Division of EDF SA. Before joining EDF she held a position of Assistant Professor at the Polytechnic Institute of Porto (20002005) and a research position at Imperial College London (2005-2009). Her research interests include integration of intermittent generation, demand side management and electric vehicles. She was a member of former CIGRE WG C6.09 on Demand Side Response.

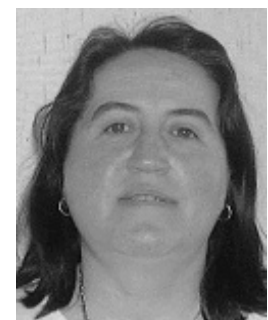

Régine Belhomme (S'83, M'91) received the Electrical Engineering degree in 1986 and the $\mathrm{PhD}$ degree in 1990, both from the University of Liège, Belgium. She is Project Manager and Senior Engineer in the Department of Economic and Technical Analysis of Energy Systems, in the R\&D Division of EDF SA. Before joining EDF, she was with the Research Institute of Hydro-Quebec (IREQ), Canada, where she carried out studies on the integration of Distributed Generation (DG) into the Hydro-Quebec distribution network. She joined EDF R\&D in 1998 and her main activities first concerned the integration of DG and Renewables into transmission and distribution power systems. She is now involved in activities on demand side integration and the development of active demand. She is the Technical Manager of the ADDRESS European Project. She is a member of IEEE, CIGRE and SEE. She was a member of former CIGRE WG C6.09 on "Demand Side Response" and she is a member of CIGRE WG C6.20 on the "Integration of electric vehicles into power systems".

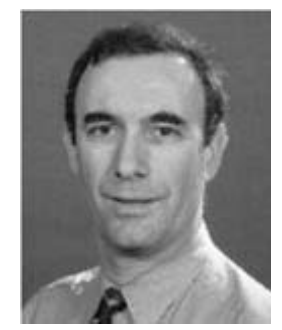

Daniel S. Kirschen (M'86, SM'91, F'07) received the electrical and mechanical engineer's degrees from the Université Libre de Bruxelles, Belgium, in 1979 and the M.S. and Ph.D. degrees from the University of Wisconsin, Madison, in 1980 and 1985, respectively. He is currently Close Professor in Electrical Engineering at the University of Washington.

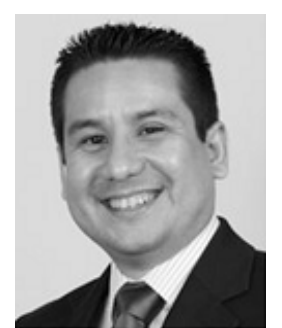

Luis F. Ochoa (S'01, M'07, SM'12) received the B.Eng. degree from UNI, Lima, Peru, in 2000 and the M.Sc. and Ph.D. degrees from UNESP, Ilha Solteira, Brazil, in 2003 and 2006, respectively.

$\mathrm{He}$ is a Lecturer in Smart Distribution Networks at The University of Manchester, UK. His current research interests include network integration of distributed energy resources and low-carbon future distribution networks. 